\title{
Severe Extrapyramidal Syndrome Caused by Lurasidone Low Dose
}

Sir,

Second-generation antipsychotics (SGAs) are

found to be safer in comparison to first-generation antipsychotics in producing extrapyramidal side effects. Lurasidone had shown good efficacy in schizophrenia as well as bipolar disorder. ${ }^{[1,2]}$ It has similar affinity for the dopamine D2 and serotonin 5-HT2A receptors and a much greater affinity for 5-HT7, 5-HT1A, and a2C-adrenergic subtype receptors than other atypical antipsychotics. As antagonism of 5-HT7 can improve cognition, memory, and mood symptoms, lurasidone is preferred in many clinical situations above other SGAs. The common side effects of lurasidone are nausea, vomiting, akathisia, dizziness, and sedation. Lurasidone 
causing very severe extrapyramidal syndrome (EPS) is not so common. ${ }^{[3,4]}$ Here, we are presenting a case who presented with very severe EPS with intake of low dose of lurasidone.

Mrs. M, a 33-year-old married female living with her husband and four children, with well-adjusted premorbid personality and no significant personal and family history, presented with illness duration of 2 years which is insidious in onset and episodic in the course. On the background of interpersonal relationship issues with husband since marriage, she had first episode of illness with symptoms characterized by pervasive low mood, easy fatigability, anhedonia, social withdrawal, and reduced appetite. Following this, in the past 2 years, she had multiple similar episodes lasting for 1 month at a frequency of once in 5 months. The patient was started on escitalopram 4 months back. She showed good improvement in terms of the above-said symptoms. While on escitalopram, she presented with symptoms of reduced need for sleep, increased activity level, overcheerfulness, overspending, tall claims, and aggressive behavior. After this, escitalopram was stopped, then she was started on olanzapine, and eventually lithium was started with which she showed complete improvement in her symptoms, after which she was discharged. Within 1 month of discharge, she again showed depressive symptoms. Following this, olanzapine was stopped and quetiapine was started which she was not able to tolerate due to high sedation. Later, she was started on lurasidone 20 which was later hiked up to $80 \mathrm{mg}$. After 2 weeks of starting lurasidone, she came for follow-up reporting that she was not feeling comfortable with $80 \mathrm{mg}$ of lurasidone and she was taking only $40 \mathrm{mg}$ of it. On examination, she showed bilateral tremors, the rigidity of both upper and lower limb including the trunk, and stiff gait suggestive of extrapyramidal side effects. She scored 16 on Simpson-Angus Extrapyramidal side effect scale. Following this, lurasidone was stopped and lamotrigine was started. She was followed-up thrice over the next 3 months, during which no extrapyramidal signs were noted and she was maintaining well.

Lurasidone in low dose $(40 \mathrm{mg})$ is not known to cause very severe EPS. Here, our patient developed generalized EPS scoring 16 in SAS. Need for adding anticholinergic increases when lurasidone is escalated from $40 \mathrm{mg}$ to higher doses. ${ }^{[3]}$ Lurasidone has a potent affinity for dopamine $\mathrm{D}_{2}$ and $5-\mathrm{HT}_{2 \mathrm{~A}}$ receptors; however, unlike most SGAs, it completely lacks binding affinity for histamine $\mathrm{H}_{1}$ and muscarinic receptors. Probably, 5-HT1A receptor activation attenuates EPS induced by dopamine $\mathrm{D}_{2}$ blockade. Furthermore, lurasidone has least cataleptogenic activities, of which the reasons are still unclear. ${ }^{[1]}$ However, our case showed significant disability due to severe EPS which aroused the possibility of other neurological disorders even though central nervous system examination was normal. Lurasidone is a well-suited drug for mood, anxiety, and psychotic symptoms with extra benefits of the least metabolic syndrome and high precognitive property. However, EPS produced with its low dose can reduce the efficacy and tolerability, leading to poor compliance. The case of lurasidone $40 \mathrm{mg}$ causing such severe EPS with no earlier history of EPS with olanzapine and quetiapine is extremely rare. It could be due to high receptor affinity in a particular person and specific genetic variants. ${ }^{[2,3]}$

Hence, we should be cautious even while writing comparatively safer and newer SGA and should not forget the propensity to develop EPS even in lower doses.

\section{Declaration of patient consent}

The authors certify that they have obtained all appropriate patient consent forms. In the form the patient(s) has/have given his/her/their consent for his/ her/their images and other clinical information to be reported in the journal. The patients understand that their names and initials will not be published and due efforts will be made to conceal their identity, but anonymity cannot be guaranteed.

\section{Financial support and sponsorship}

Nil.

\section{Conflicts of interest}

There are no conflicts of interest.

Soumitra Das, Bhaskaran Subramaniyam Andi

Department of Psychiatry, National Institute of Mental Health and Neuroscience, Bengaluru, Karnataka, India

Address for correspondence: Dr. Soumitra Das, Department of Psychiatry, National Institute of Mental Health and Neuroscience, Bengaluru - 560 029, Karnataka, India. E-mail: soumitra_nimhans@yahoo.com

\section{REFERENCES}

1. Ishibashi $\mathrm{T}$, Horisawa $\mathrm{T}$, Tokuda $\mathrm{K}$, Ishiyama $\mathrm{T}$, Ogasa $\mathrm{M}$, Tagashira $\mathrm{R}$, et al. Pharmacological profile of lurasidone, a novel antipsychotic agent with potent 5-hydroxytryptamine 7 (5-HT7) and 5-HT1A receptor activity. J Pharmacol Exp Ther 2010;334:171-81.

2. Paul S, Cooke BK, Nguyen M. Glossopharyngeal dystonia secondary to a lurasidone-fluoxetine CYP-3A4 interaction. Case Rep Psychiatry 2013;2013:136194.

3. Tricia Lemieux B, Sopko MA Jr., Ehret MJ. Focus on lurasidone: A new atypical antipsychotic for the treatment of schizophrenia. Formulary. 2010;45:313-7. Available 
from: http://www.formularyjournal.modernmedicine.com/ formulary-journal/news/clinical/clinical-pharmacology/ focus-lurasidone-new-atypical-antipsychotic-tr?page=full. $\quad$ [Last accessed on 2017 Oct 15].

4. Das S, Agrawal A. Lurasidone-induced oculogyric crisis. Indian J Psychol Med 2017;39:719-20.
This is an open access journal, and articles are distributed under the terms of the Creative Commons Attribution-NonCommercial-ShareAlike 4.0 License, which allows others to remix, tweak, and build upon the work non-commercially, as long as appropriate credit is given and the new creations are licensed under the identical terms.

\begin{tabular}{|l|l|}
\hline \multicolumn{2}{c|}{ Access this article online } \\
\hline Quick Response Code: & Website: \\
\hline
\end{tabular}

How to cite this article: Das S, Andi BS. Severe extrapyramidal syndrome caused by lurasidone low dose. J Neurosci Rural Pract 2018;9:446-8.

C 2018 Journal of Neurosciences in Rural Practice | Published by Wolters Kluwer - Medknow 